\title{
Intralesional fenestration and corticosteroid injection for symptomatic Ledderhose disease of the foot: two case reports
}

\section{George Flanagan ( $\nabla$ gflanagan@nhs.net )}

Northamptonshire Healthcare Foundation NHS Trust https://orcid.org/0000-0002-5166-7580 Nicola Burt

Northamptonshire Healthcare Foundation NHS Trust https://orcid.org/0000-0002-6464-920X lan Reilly

Northamptonshire Healthcare Foundation NHS Trust https://orcid.org/0000-0002-2786-5739

\section{Case Report}

Keywords: Ledderhose, fibromatosis, corticosteroid, plantar, triamcinolone, fenestration, needling, peppering

Posted Date: December 7th, 2020

DOI: https://doi.org/10.21203/rs.3.rs-123430/v1

License: (c) (i) This work is licensed under a Creative Commons Attribution 4.0 International License. Read Full License 


\section{Abstract}

The description of corticosteroid injection as a treatment option for Ledderhose disease has received little attention in the literature and often merely receives a passing comment in scientific papers. We present a short case series of two patients that underwent corticosteroid injection in combination with fenestration to treat painful Ledderhose disease nodules. Both patients had their lesions injected on two occasions. Significant reduction in pain and lesion volume was seen at 12 months post treatment. Our protocol combines fenestration with the use of triamcinolone acetonide (mixed with local anaesthetic) which we believe conveys further advantage over corticosteroid infiltration alone.

\section{Introduction}

The fibromatoses encompass a broad array of proliferative fibroblastic disorders which can be defined by location (superficial or deep) and biological behaviour (benign, intermediate and aggressive) ${ }^{1}$. They share common histological appearances which include spindle shaped myofibroblasts, significant intercellular collagen fibres, compressed and elongated vessels and varying appearances of extracellular myxoid matrix ${ }^{2}$. Ledderhose disease (LD) belongs to a family of superficial fibroblastic proliferative diseases that includes Dupuytren's disease of the palmar fascia (palmar fibromatosis) and Peyronie's disease (penile fibromatosis). LD was originally described by Dr George Ledderhose in $1894^{3}$. Also known as plantar fibromatosis, morbus Ledderhose and Dupuytren's disease of the plantar fascia, LD is a relatively uncommon benign fibrous proliferation of the plantar fascia (aponeurosis).

Many aetiological factors have been described in the literature. Males are at twice the risk of developing LD, in addition, diabetes, nicotine use, medication (phenobarbital and anti TNF), alcohol misuse and genetic predisposition have all been cited as risk factors ${ }^{4}$. A high failure and recurrence rate for the surgical treatment of LD is well documented ${ }^{4}$.

Despite the poor outcomes associated with the surgical treatment of LD, surgery still accounts for the majority of published evidence available. A variety of non-surgical options exist with variable outcomes ${ }^{4}$. Fenestration (needling) +/- corticosteroid injection is a well described technique for many soft tissue pathologies including plantar fasciitis ${ }^{5}$. For the last five years we have adapted a fenestration and corticosteroid technique for LD nodules with anecdotally excellent results in terms of both symptom relief and reduction in nodule rigidity and size.

In developing this paper, the authors adopted a search strategy that involved looking for research evidence via electronic databases and reference lists, cross referencing 'steroid injection' with LD and 
'fenestration' or 'needling". As far as the authors are aware this approach to the treatment of LD has not previously been reported.

\section{Case Report 1}

History

A 54-year-old male originally presented to his primary care physician in January of 2019 complaining of two painful swellings in the sole of his left foot. An ultrasound examination was requested. Two well defined hypoechoic lesions arising from the distal portion of the left plantar fascia were described. The distal lesion measured $13.5 \mathrm{~mm}$ in length $\times 5.2 \mathrm{~mm}$ in width (Fig. 1) the proximal lesion measured $7.9 \mathrm{~mm}$ $x 2.8 \mathrm{~mm}$ (Fig. 2). No significant intra-substance vascularity was seen. The remaining plantar fascia was normal. Appearances were in keeping with LD.

The patient had a history of nicotine use (15-20 cigarettes a day), essential hypertension and chronic lumbar region pain. He had stable epilepsy and was recovering from alcohol abuse. Medication included lisinopril $20 \mathrm{mg}$ od, gabapentin $400 \mathrm{mg}$ tds, codeine $30 \mathrm{mg} /$ paracetamol $500 \mathrm{mg}$ combination prn and sodium valproate $500 \mathrm{mg}$ tds. The patient had concomitant palmar Dupuytren's disease on the left hand with fascial nodules and contracture of the $4^{\text {th }}$ finger. There were no known allergies and no relevant family or surgical history.

Following the results of the ultrasound scan organised in primary care, he was seen by our service in February 2019 complaining of searing pain on the medial longitudinal arch of the left foot of six months duration. He described the pain as severe and debilitating and rated his discomfort at 9/10 on a visual analogue scale (VAS). On examination he had two firm, sub-epidermal swellings in the distal-medial aspect of the arch associated with the central slip of the plantar fascia. Normal neurovascular status was observed. His symptoms had worsened over the previous three months, aggravated by activity and weightbearing. Prior treatment included accommodative footwear and orthoses. Intralesional corticosteroid in combination with a fenestration/needling was recommended.

\section{Procedure}

One week following initial consultation the patient attended for their planned procedure. As the patient presented with significant pain, the procedure was performed under tibial nerve block, performed at the level of the ankle with $3 \mathrm{ml}$ of $0.75 \%$ ropivacaine under aseptic technique. The injection sites were prepared with a chlorhexidine gluconate $2 \%$ / isopropyl alcohol $70 \%$ mix. A sterile cover was placed on the ultrasound probe and sterile coupling gel utilised. The ultrasound probe was placed plantarly and 
longitudinal to the lesion to allow for a medial injection approach. A mixture of $20 \mathrm{mg}(40 \mathrm{mg} / \mathrm{ml})$ triamcinolone acetonide and $1 \mathrm{ml}$ of mepivacaine hydrochloride was deposited with intralesional fenestration (20-30 repeated passes with multiple small deposition sites from proximal to distal and medial to lateral without removing the needle from the skin) initially to the distal lesion followed by an identical preparation administered to the proximal lesion. Both injections were performed under ultrasound guidance with confirmation of intralesional deposition. An extremely small amount of perilesional injectate leakage was noted. Importantly a $2.5 \mathrm{ml}$ Luer lock syringe with a 23 gauge/ $25 \mathrm{~mm}$ needle was utilised as experience has shown the presence of pressure when injecting a solid mass which can cause de-coupling of the syringe from needle. No significant bleeding was associated with the procedure. A simple self-adhesive dressing was applied to the injection sites.

Post procedure advice included rest and foot elevation for the remaining day. The patient could return to daily living activities the following day but was to refrain from impact activity e.g., sports until follow up at six weeks post procedure. As well as the usual post-injection advice, particular reference to the small risk of fascial rupture was made.

\section{Follow up}

No significant beneficial effect was witnessed at the six-week review, as such, a second injection was recommended. Eight weeks following the original procedure the same protocol as described above was undertaken. In this instance palpation guided injection and fenestration was undertaken (fig. 3). Six weeks post the second procedure (total 14 weeks post index procedure) a significant reduction in the size and rigidity of both lesions was reported clinically. A repeated VAS was 2/10.

For purposes of audit the patient was reviewed at twelve months post procedure and a further ultrasound examination was undertaken showing a significant regression of both nodules, the distal nodule to $6 \mathrm{~mm}$ $x 1.9 \mathrm{~mm}$ (Fig. 4) and the proximal nodule to $2.4 \mathrm{~mm} \times 1.2 \mathrm{~mm}$ (Fig. 5). During this period the patient had no regression of symptoms. A VAS completed at twelve months was $0 / 10$. Clinically the proximal nodule was no longer palpable or visible, the distal nodule remained palpable but not visible. No pain was felt on palpation. The patient remarked they were unable to feel any nodule on ambulation. No adverse signs or symptoms were reported.

\section{Case Report 2}

History 
A 55-year-old female attended our service in August 2017 complaining of bilateral plantar nodules, at initial presentation only the right foot was symptomatic. The patient's medical history included type 2 diabetes mellitus of 12 years duration (recent HbA1c $52 \mathrm{mmol} / \mathrm{mol}$ ) and essential hypertension. Medications included empagliflozin $10 \mathrm{mg}$ od, linagliptin $5 \mathrm{mg}$ od, gliclazide $80 \mathrm{mg}$ bd, ramipril $10 \mathrm{mg}$ od, atenolol $50 \mathrm{mg}$ od and amlodipine $15 \mathrm{mg}$ nocte. There were no known allergies and no relevant family/social or surgical history.

When assessed the patient described a 12-month history of a symptomatic mass within the medial longitudinal arch of the left foot, a VAS of 8/10. Symptoms were exacerbated by prolonged periods of ambulation and weightbearing. Orthoses and footwear adaptation had not yielded any symptomatic reprieve. Clinically a solitary mass could be palpated within the medial longitudinal arch of the right foot, tenderness was apparent on palpation. The mass was rigid, overlying tissue unremarkable. Neurovascular observations were unremarkable. Subsequently an ultrasound examination was requested (Fig. 6). The proximal plantar fascia appeared normal however a large solitary well defined hypoechoic mass was seen within the medial band of the plantar fascia measuring $24.1 \mathrm{~mm}$ in length and $7 \mathrm{~mm}$ in width. Appearances again were consistent with LD.

\section{Procedure}

Similarly, as conservative treatment options had failed so far, corticosteroid injection was suggested. In September 2017 the patient underwent a single injection (no fenestration) of $40 \mathrm{mg}(40 \mathrm{mg} / \mathrm{ml})$ methylprednisolone with lidocaine under ultrasound guidance. Whilst moderate improvement was seen at six weeks post procedure the patient returned three months following the procedure noting complete recurrence of symptoms. The patient was subsequently listed for the described technique of triamcinolone acetate fenestration under ultrasound guidance. This was performed in March 2018, the injection technique mirrored that described in case study one. Similarly to case study one, due to only moderate improvement at early review (six weeks) a second fenestrated injection was scheduled. This was undertaken later (Nov 2018) due to variable availability issues. At six months post final procedure the patient reported VAS as $1 / 10$ and return to full activities.

For audit purposes the patient was contacted for review at twelve months post procedure and ultrasound examination performed. VAS at twelve months post procedure was $0 / 10$, clinically the mass showed almost complete resolution with only minimal deciphering on palpation. No adverse signs or symptoms were noted. The ultrasound was reported as showing a remaining hypoechoic mass sited in the same area as previously demonstrated but with reduced dimensions as seen in Fig. 7. 


\section{Discussion}

The use of corticosteroid injection for Dupuytren's disease has been reported in the hand ${ }^{6}$ and their use for LD in the foot has been discussed (often only in passing) by various authors ${ }^{4,7,8,9}$. Local steroid injections reduce the rate of fibroblast proliferation and increase the rate of apoptosis ${ }^{10}$. Ketchum at al ${ }^{11}$ had previously demonstrated that triamcinolone acetonide softened and flattened hypertrophic scars and keloids and that it degraded the insoluble collagen in hypertrophic scars and keloids to salt-soluble collagen, which was then absorbed and excreted. In a retrospective study ${ }^{12}, 63$ patients with Dupuytren's nodules in the early stages of disease underwent a series of triamcinolone acetonide injections. Each injection contained $60-120 \mathrm{mg}$ of triamcinolone administered directly into nodule(s) of patients with contracture of less than 15 degrees. 97\% (62/63) of patients experienced regression of the disease exhibited as softening or flattening of nodules, with an average of 3.2 injections per nodule reported. Some had complete resolution of the nodule but more (60-80\%) experienced definite but incomplete resolution. Although immediate regression of nodules was generally observed, many experienced recurrences and around half of those required further injections 1-3 years after their initial treatment.

Pentland and Anderson ${ }^{8}$ presented a case study of a patient with bilateral multi-nodular plantar fibromas, recurrent on the right foot after excisional surgery ten years previously. The patient received five intralesional injections at monthly intervals of $0.5-1.0 \mathrm{ml}$ of triamcinolone acetonide diluted $3: 1$ with $1 \%$ lidocaine hydrochloride to a final concentration of $30 \mathrm{mg} / \mathrm{ml}$. The reader assumes that each of the lesion had that dose. Considerable softening of the lesions was noted and four months after the final injection the patient was able to resume jogging. They discuss the conflicting results of the effect of corticosteroid injections on in vitro fibroblast collagen production but promote corticosteroid for LD.

A 'peppering' technique was first described in $1964^{13}$ and later popularised clinically for lateral epicondylitis ${ }^{14}$. Peppering, needling and fenestration are all terms used in the literature across professional groups and across pathologies, in particular plantar fasciitis. We prefer the term fenestration as we aim to create channels within the lesion. We hypothesise that this has the effect of physically breaking down scar tissue while providing an effective portal of entry for the corticosteroid. As such we believe that fenestration confers greater efficacy than use of corticosteroid injection alone.

Whilst it has been stated that a number of classification systems exist ${ }^{4}$, the only noted staging system is that developed by Sammarco and Mangone ${ }^{15}$. They produced a four-stage operative classification system incorporating the extent of fascial involvement, the presence of skin adherence and the depth of tumour extension. The remaining classification systems used for LD are derived from the work of Luck ${ }^{16}$ 
in staging Dupuytren's disease. The proliferative stage is characterised by increased fibroblastic activity and reduced collagen network, followed by the active or involutional stage showing fibroblast maturation, myofibroblast differentiation and increased collagen synthesis. A final residual stage displays both reduced fibroblast and collagen maturation.

Whilst it has been opined that corticosteroid injection would specifically help with collagen breakdown at the residual (end) phase of a chronic LD nodule ${ }^{17}$, corticosteroid injection has been shown to suppress VLA-4 a common integrin integral to cell adhesion in early inflammation ${ }^{18}$.

The authors have treated over twenty-five patients with the procedure described in the text, whilst outcome data for those patients is anecdotal and/or preserved within medical notes, the authors subjectively believe that the majority of patients show significant improvement with the particular combination of fenestrated triamcinolone acetate with a small amount of local anaesthetic. It is recognised that the variability of local anaesthetic as part of the injectate may influence outcomes, as local anaesthetic itself has been shown to cause apoptosis ${ }^{19}$. Case report two has previously trialled a single injection of methylprednisolone and lidocaine, this was followed by a quick and complete return of symptoms: this is a trend seen anecdotally within our service with the use of methylprednisolone.

Whilst a tibial anaesthetic block allowed for procedural anaesthesia in case report one, it should be noted that the majority of patients tolerate local infiltration and fenestration with local anaesthetic added to the injectate only. The use - or not - of concurrent ultrasound guidance is a further matter that is open for debate. Typically, the lesions are sub dermal and easy to identify with the needle tip. With our small case series and anecdotal feedback, we are not in a position to state whether the use of ultrasound is an advantage or not. Certainly in those lesions not discernible by palpation then the use of ultrasound guidance is suggested. We have not, to our knowledge, seen a case of fascial rupture or significant tissue atrophy post corticosteroid injection / fenestration but of course this remains a concern. However, given that the surgical option is excision (narrow or wide margin) or sub-total fasciectomy, the occurrence of a partial tear could be considered to be of minimal concern. The authors do however note the mounting evidence to support the use of ultrasound guided injection, particularly in this anatomical region ${ }^{20}$. Whilst described as an uncommon condition ${ }^{21}$, Bakotic and Borkowski ${ }^{22}$ found LD to be the most prevalent of all the plantar lesions identified by histopathology in a series of 401 cases.

\section{Conclusion}

Throughout this short review and a common theme in the literature cited was the need for further highlevel investigation into the effect of corticosteroid on LD nodules. While the conclusion from this case 
series is limited, we feel that the addition of fenestration to triamcinolone acetonide intralesional injection warrants further instigation. A study of sufficient size and power might suggest at what stage this intervention achieves the best outcome and if the concurrent use of ultrasound guidance conveys further advantage.

\section{Declarations}

This research did not receive any grant from funding agencies in the public, commercial, or not-for-profit sectors. All authors have no competing interests to declare. The senior author (GF) is a consultant for the British Dupuytren's Society. Organisation ethical approval was not required but the authors confirm that they adhered to virtue- and principle-based ethics when producing this work. Patient consent for publishing was obtained. All authors made substantial contributions to the work enclosed.

\section{Acknowledgements}

We acknowledge the consent given from the two patients for publication of their treatment outcomes.

\section{References}

1) Walker EA, Petscavage JM, Brian PL, Logie Cl, Montini KM, Murphey MD. Imaging features of superficial and deep fibromatoses in the adult population. Sarcoma. 2012, 2012.

2) Weiss SW, Goldblum JR, Enzinger FM. Fibromatoses. In Enzinger and Weiss' Soft Tissue Tumors, pp. 227-228, Mosby Elsevier, Philadelphia, USA, 2008.

3) Ledderhose G. Über zerreisungen der plantarfascie. Arch Klin Chir. 48:853-6, 1894.

4) Espert M, Anderson MR, Baumhauer JF. Current concepts review: plantar fibromatosis. Foot \& ankle international. 39(6):751-7, 2018.

5) Kiter E, Celikbas E, Akkaya S, Demirkan F, Kilic BA. Comparison of injection modalities in the treatment of plantar heel pain: a randomized controlled trial. Journal of the American Podiatric Medical Association. 96(4):293-6, 2016.

6) Ketchum LD, Donahue TK. The injection of nodules of Dupuytren's disease with triamcinolone acetonide. J Hand Surg Am. 25(6):1157-1162, 2000.

7) Aluisio FV, Mair SD, Hall RL. Plantar fibromatosis: treatment of primary and recurrent lesions and factors associated with recurrence. Foot \& ankle international. Nov;17(11):672-8, 1996.

8) Pentland AP, Anderson TF. Plantar fibromatosis responds to intralesional steroids. Journal of the American Academy of Dermatology. 12(1):212-4, 1985. 
9) Neagu TP, Tigliş MI, Popescu A, Enache V, Popescu ŞA, Lascăr IO. Clinical, histological and therapeutic modern approach of Ledderhose disease. Rom J Morphol Embryol. 59(3):691-7, 2018.

10) Meek RM, McLellan S, Reilly J, Crossan JF. The effect of steroids on Dupuytren's disease: role of programmed cell death. The Journal of Hand Surgery: British \& European Volume. 27(3):270-3, 2002.

11) Ketchum LD, Smith J, Robinson DW, Masters FW. The treatment of hypertrophic scar, keloid and scar contracture by triamcinolone acetonide. Plastic and Reconstructive Surgery. 38(3):209-18, 1966

12) Ketchum LD, Donahue TK. The injection of nodules of Dupuytren's disease with triamcinolone acetonide. The Journal of hand surgery. 25(6):1157-62, 2000.

13) Pruce AM, Miller Jr JA, Berger IR. Anatomic landmarks in joint paracentesis. In Clinical symposia (Summit, NJ: 1957) 16, p. 19, 1964.

14) Altay T, Günal I, Öztürk H. Local injection treatment for lateral epicondylitis. Clinical Orthopaedics and Related Research. 398:127-30, 2002.

15) Sammarco GJ, Mangone PG. Classification and treatment of plantar fibromatosis. Foot \& ankle international. 21(7):563-9, 2000.

16) Luck JV. Dupuytren's contracture: a new concept of the pathogenesis correlated with surgical management. JBJS. 41(4):635-64, 1959.

17) Downey MS. Point-Counterpoint: Is Conservative Care The Best Approach For Plantar Fibromatosis? Podiatry Today. 26(2):36-42, 2013

18) Meek RM, McLellan S, Crossan JF. Dupuytren's disease: a model for the mechanism of fibrosis and its modulation by steroids. The Journal of bone and joint surgery. British volume. 81(4):732-8, 1999.

19) Perez-Castro R, Patel S, Garavito-Aguilar ZV, Rosenberg A, Recio-Pinto E, Zhang J, Blanck TJ, Xu F. Cytotoxicity of local anesthetics in human neuronal cells. Anesthesia \& Analgesia. 108(3):997-1007, 2009.

20) Li Z, Xia C, Yu A, Qi B. Ultrasound-versus palpation-guided injection of corticosteroid for plantar fasciitis: a meta-analysis. PLoS One. 21;9(3):e92671, 2014.

21) Ledderhose Disease. National Center for Advancing Translational Sciences - Genetic and Rare Diseases Information Center. Website. March 2018. Available at: https://rarediseases.info.nih.gov/diseases/6873/ledderhose-disease. Accessed July 4th, 2020.

22) Bakotic BW, Borkowski P. Primary soft-tissue neoplasms of the foot: the clinicopathologic features of 401 cases. The Journal of foot and ankle surgery. 40(1):28-35, 2001. 


\section{Figures}

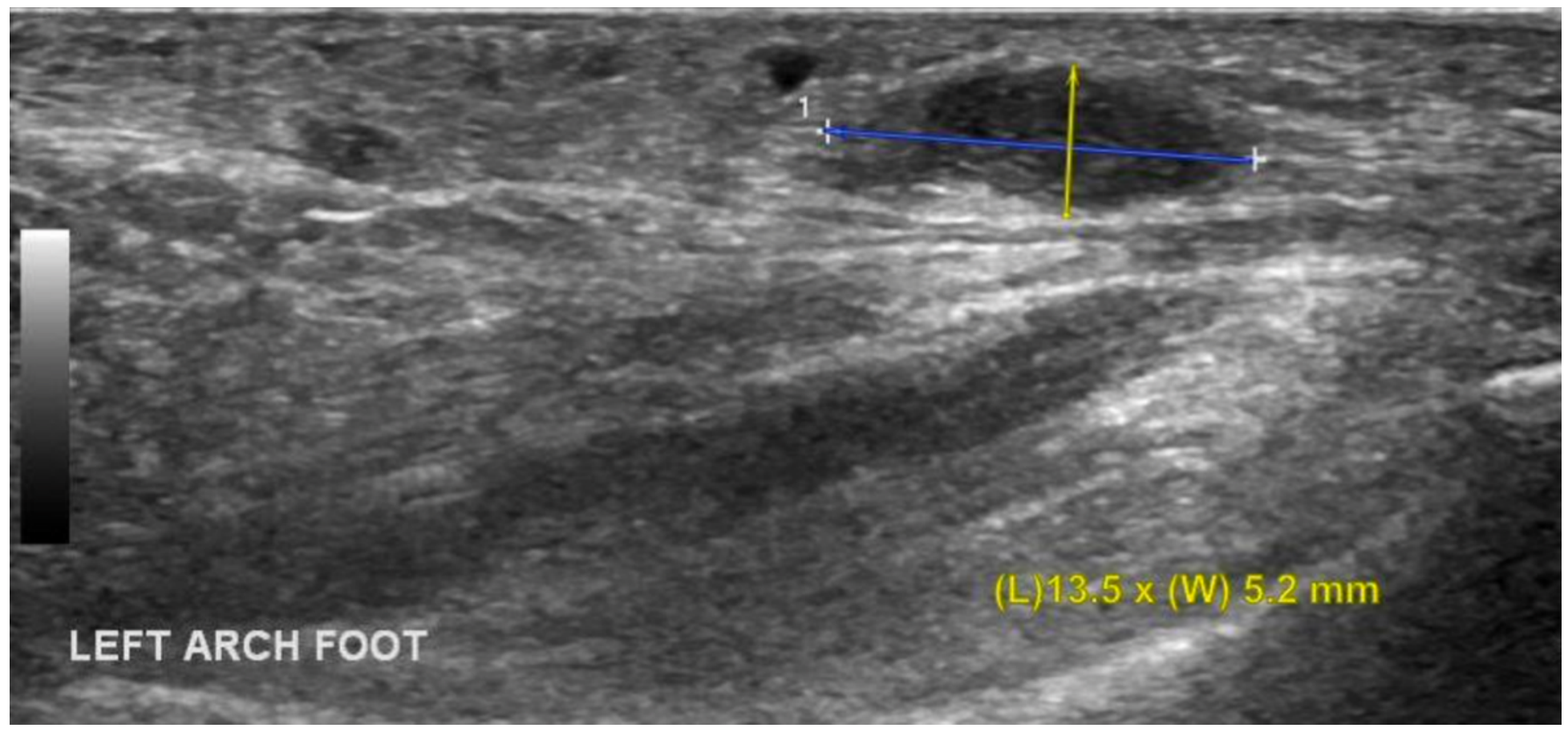

\section{Figure 1}

Case report one, distal nodule pre-treatment ultrasound scan

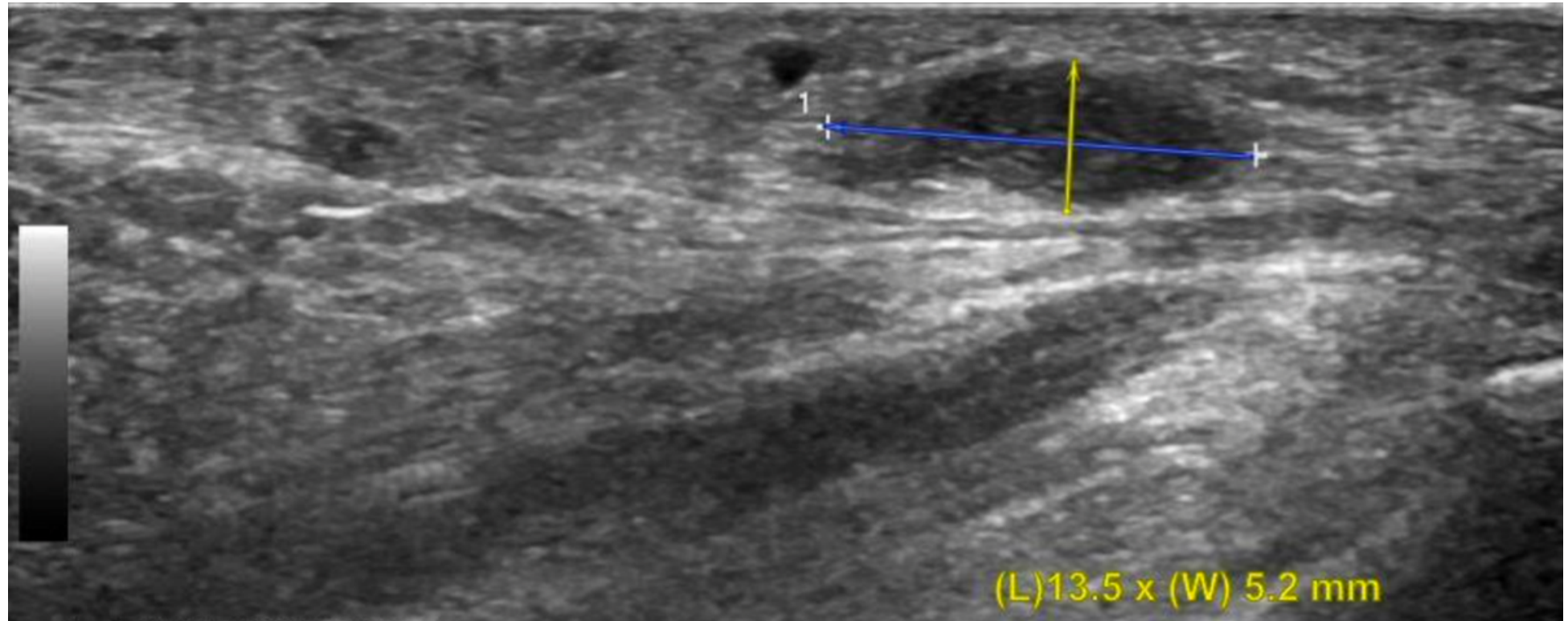

LEFT ARCH FOOT

\section{Figure 1}

Case report one, distal nodule pre-treatment ultrasound scan 


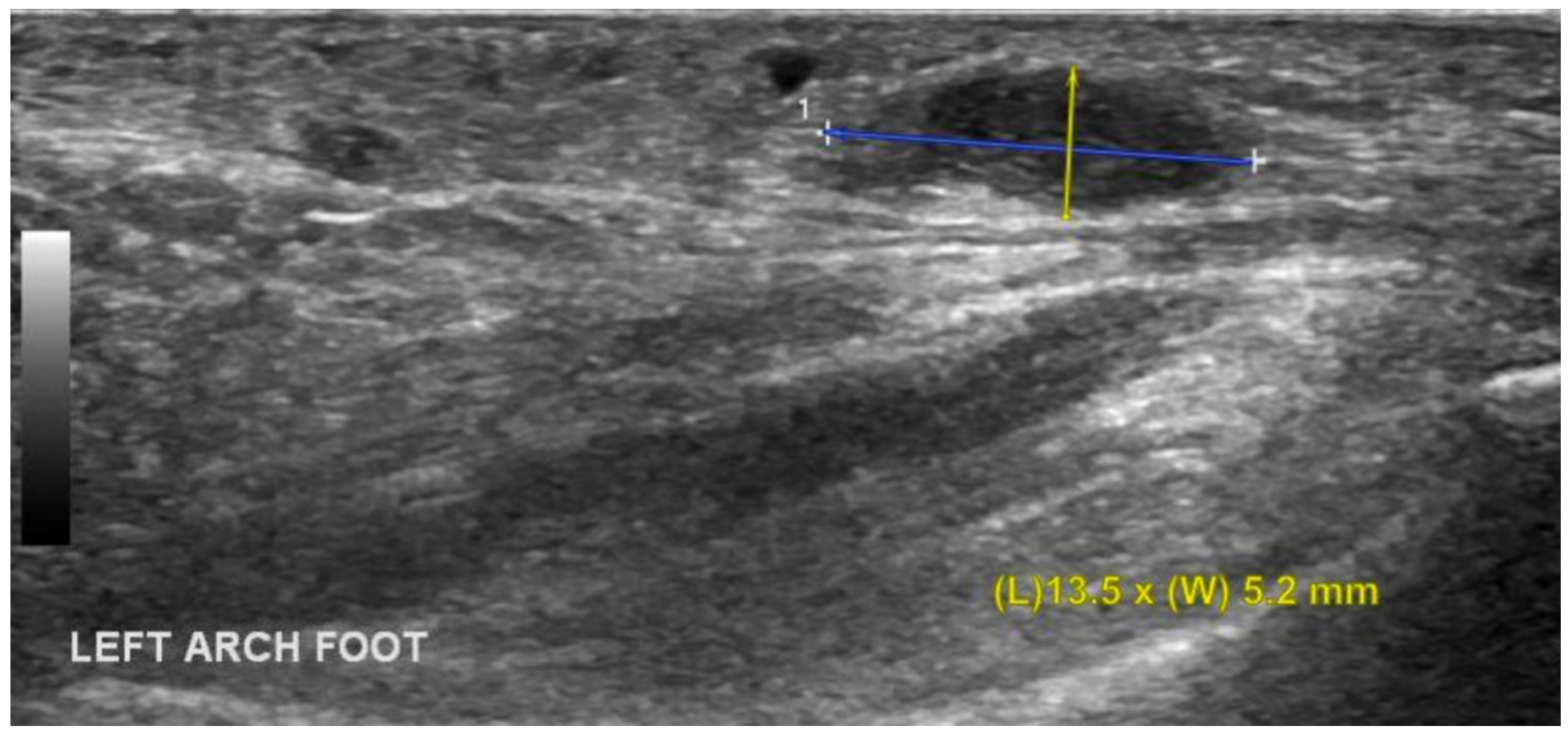

\section{Figure 1}

Case report one, distal nodule pre-treatment ultrasound scan

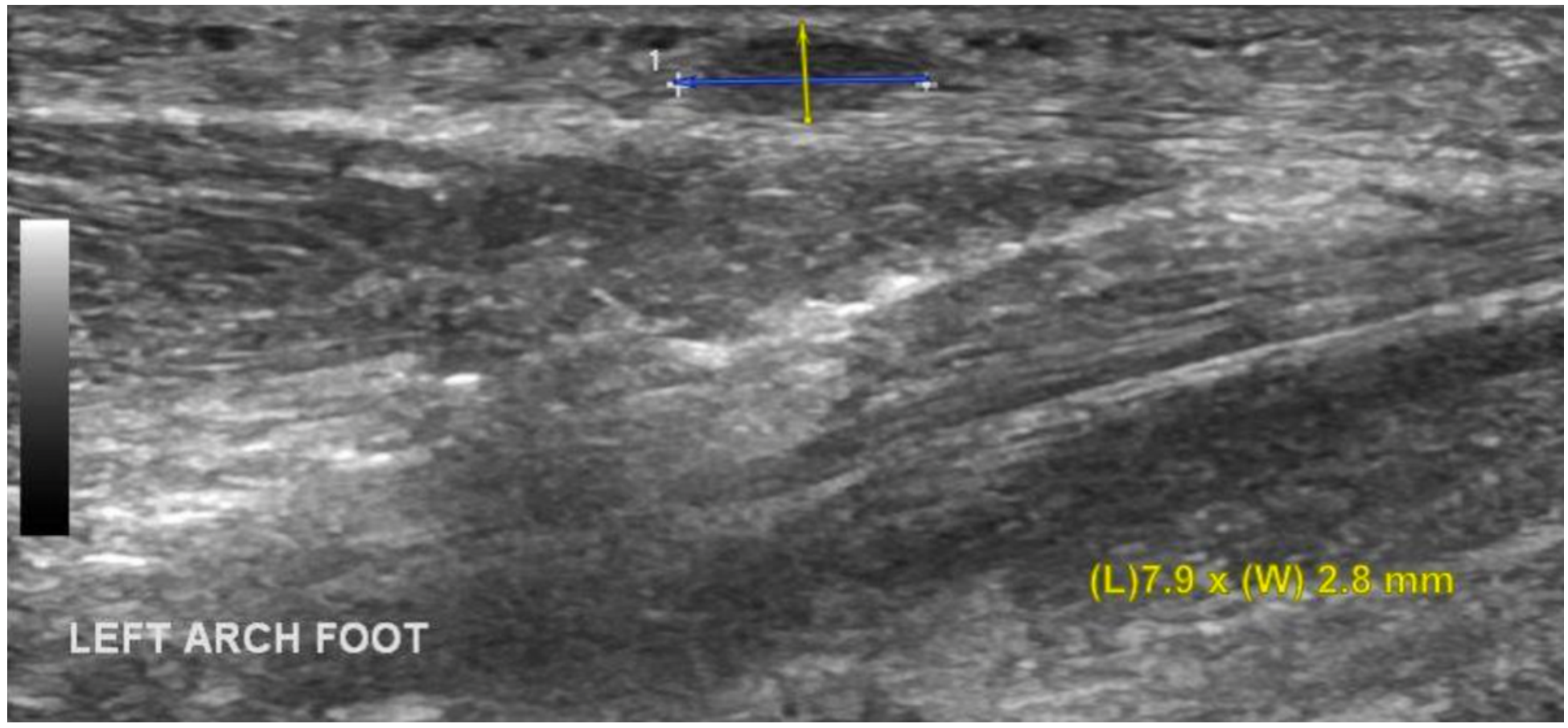

\section{Figure 2}

Case report one, proximal nodule pre-treatment ultrasound scan 


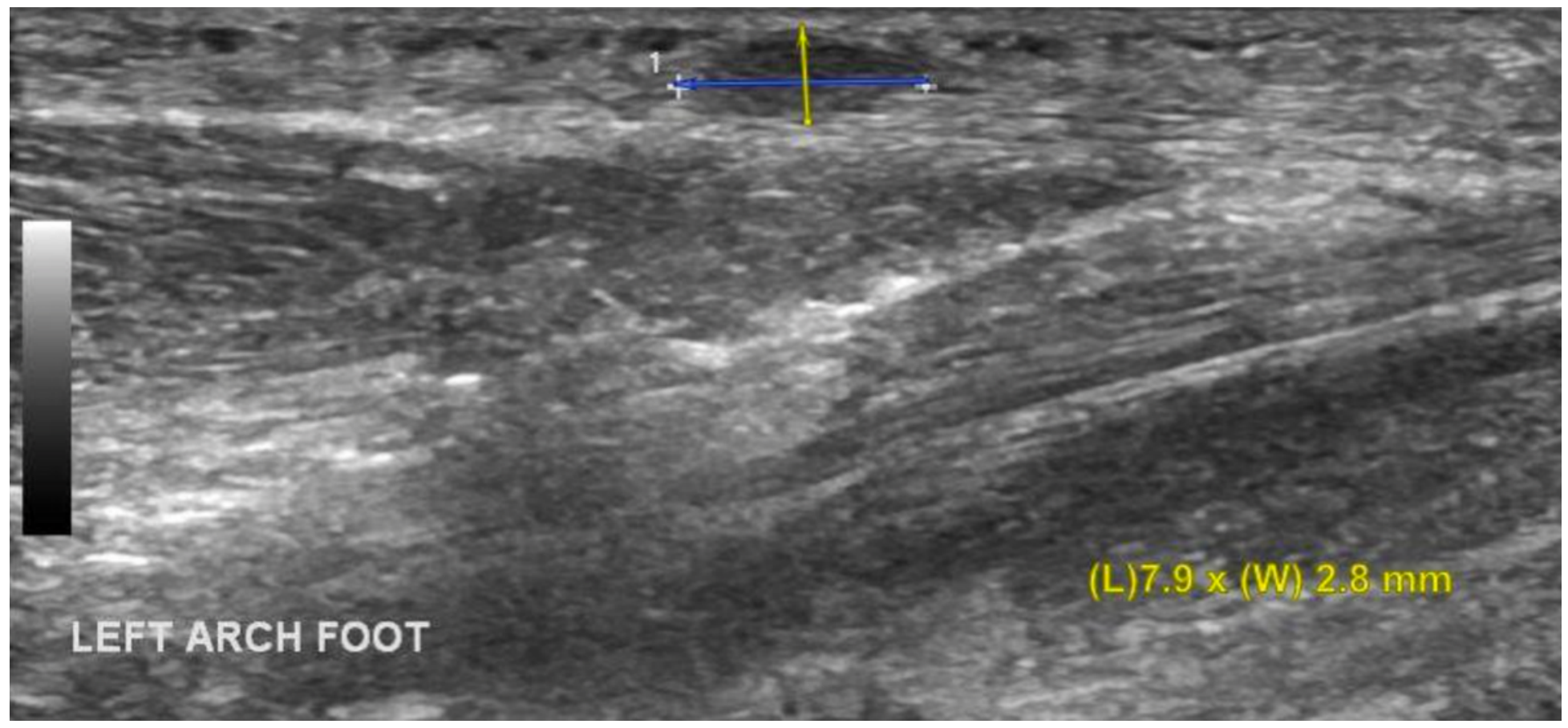

Figure 2

Case report one, proximal nodule pre-treatment ultrasound scan

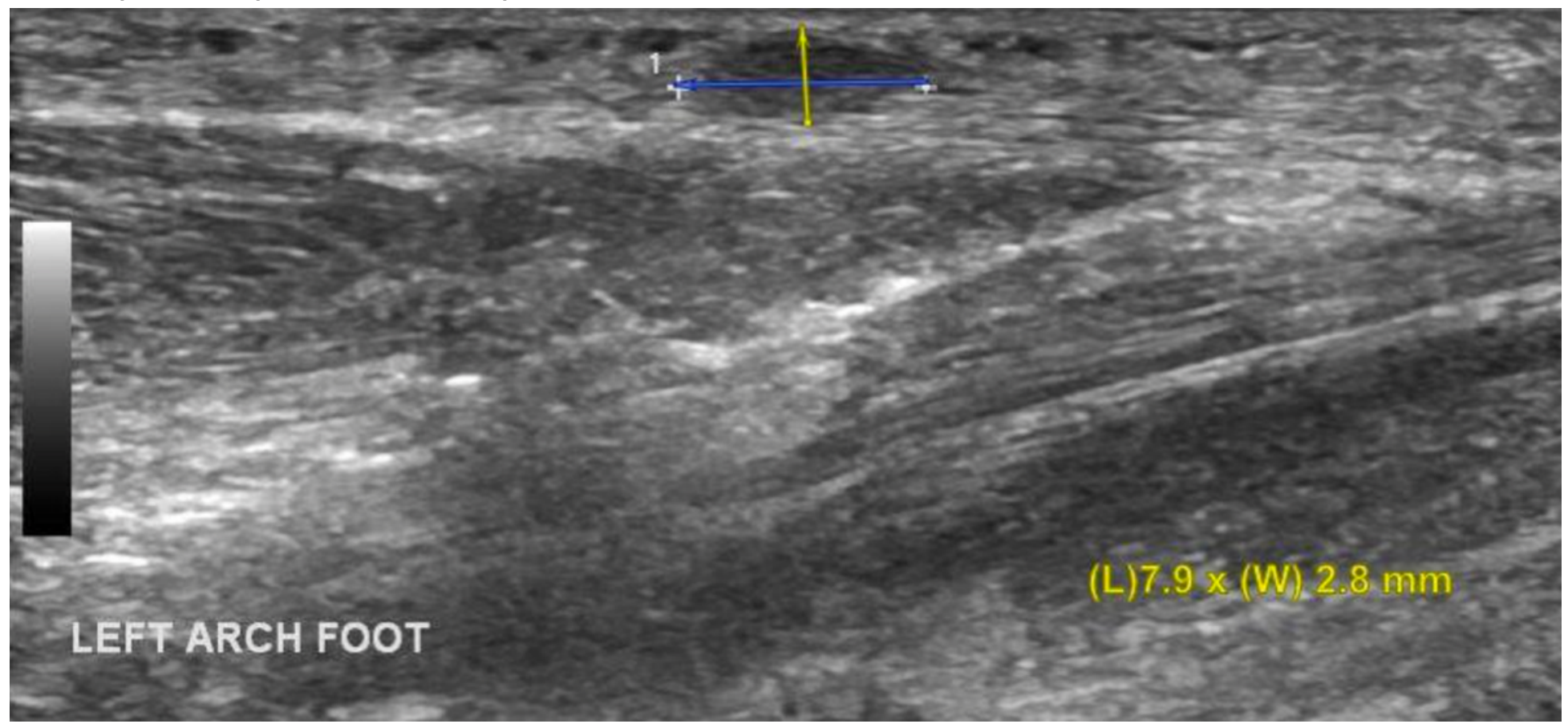

Figure 2

Case report one, proximal nodule pre-treatment ultrasound scan 


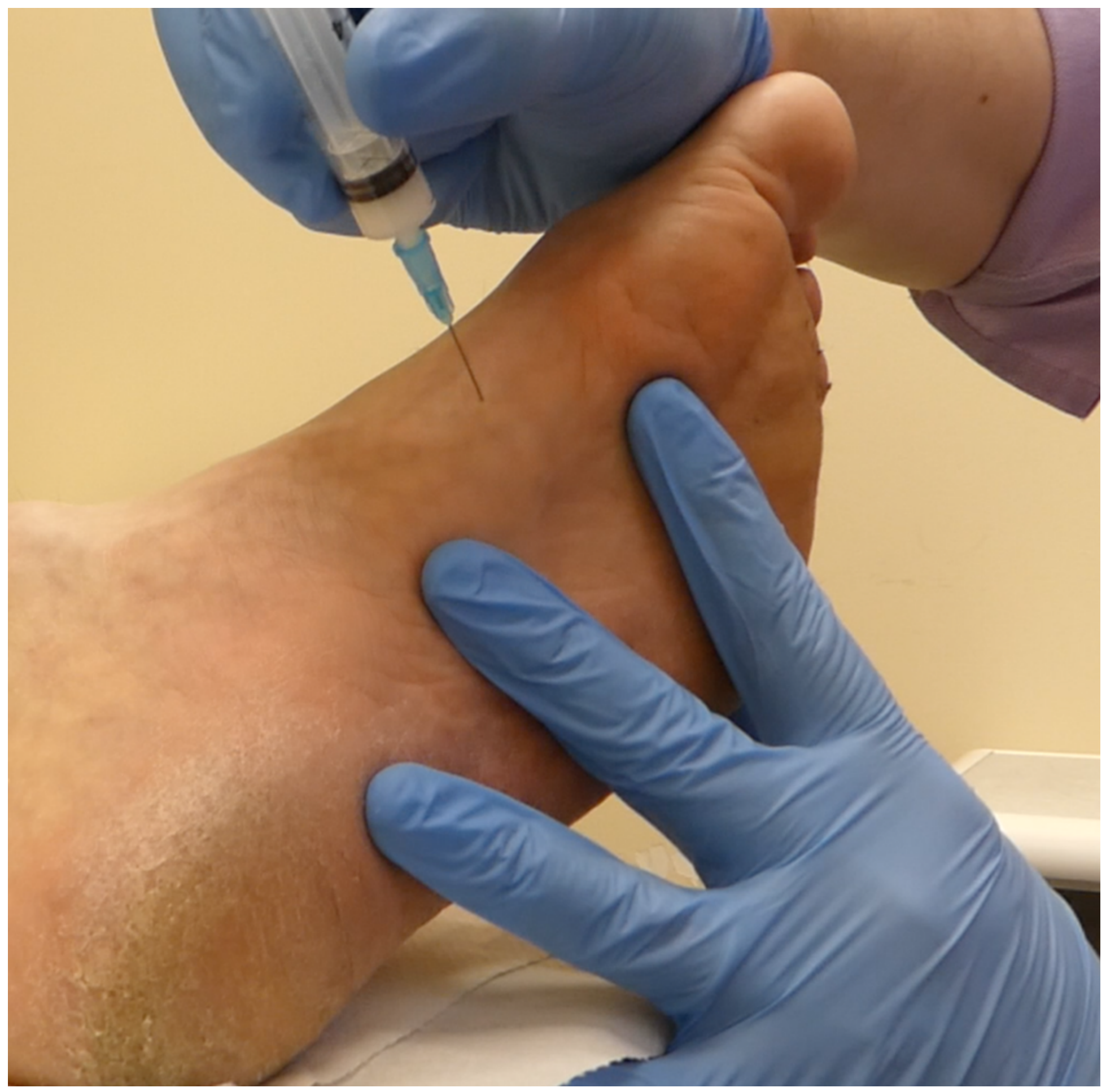

Figure 3

Case report one, palpation guided medial injection approach 


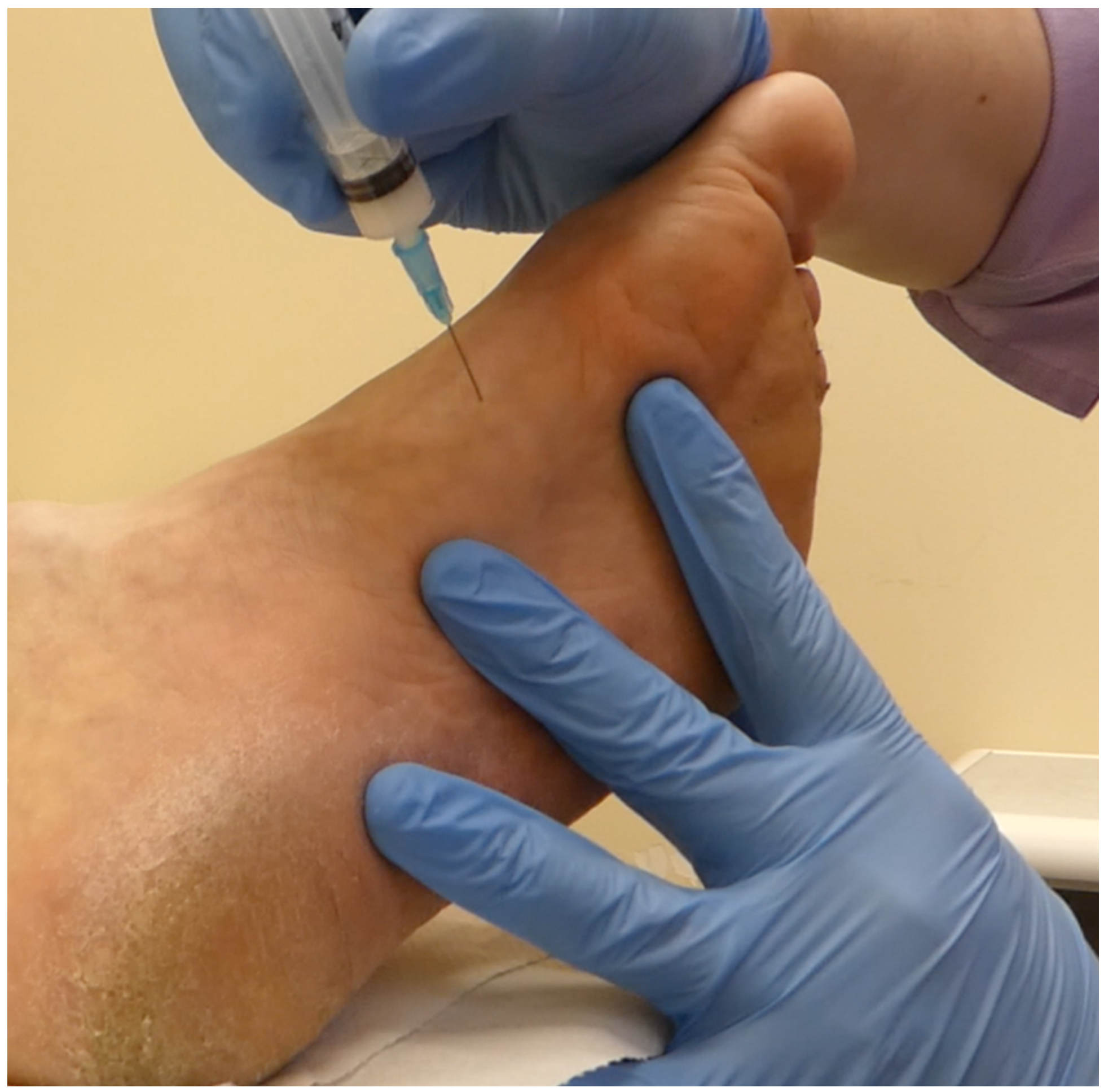

Figure 3

Case report one, palpation guided medial injection approach 


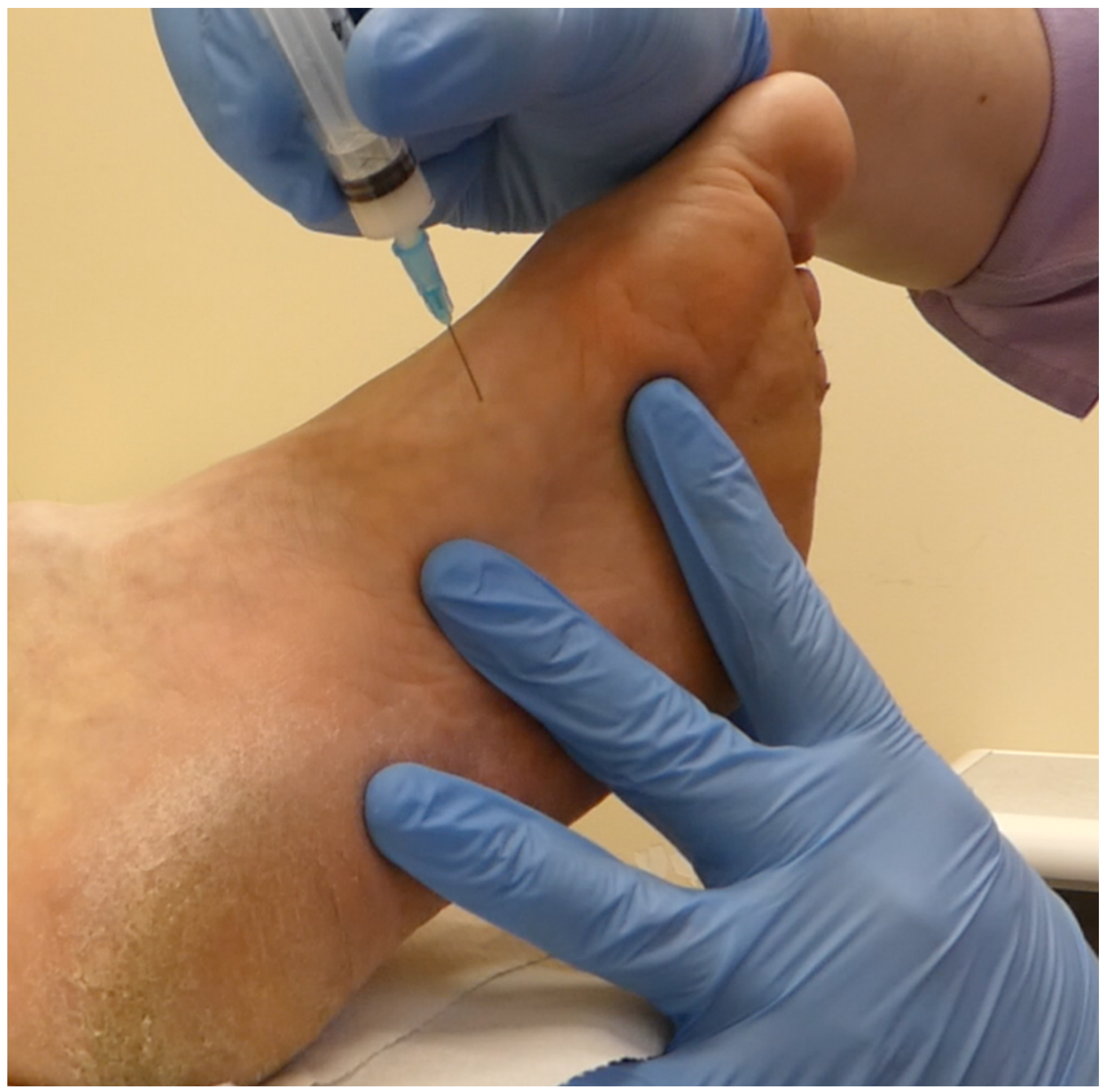

Figure 3

Case report one, palpation guided medial injection approach 


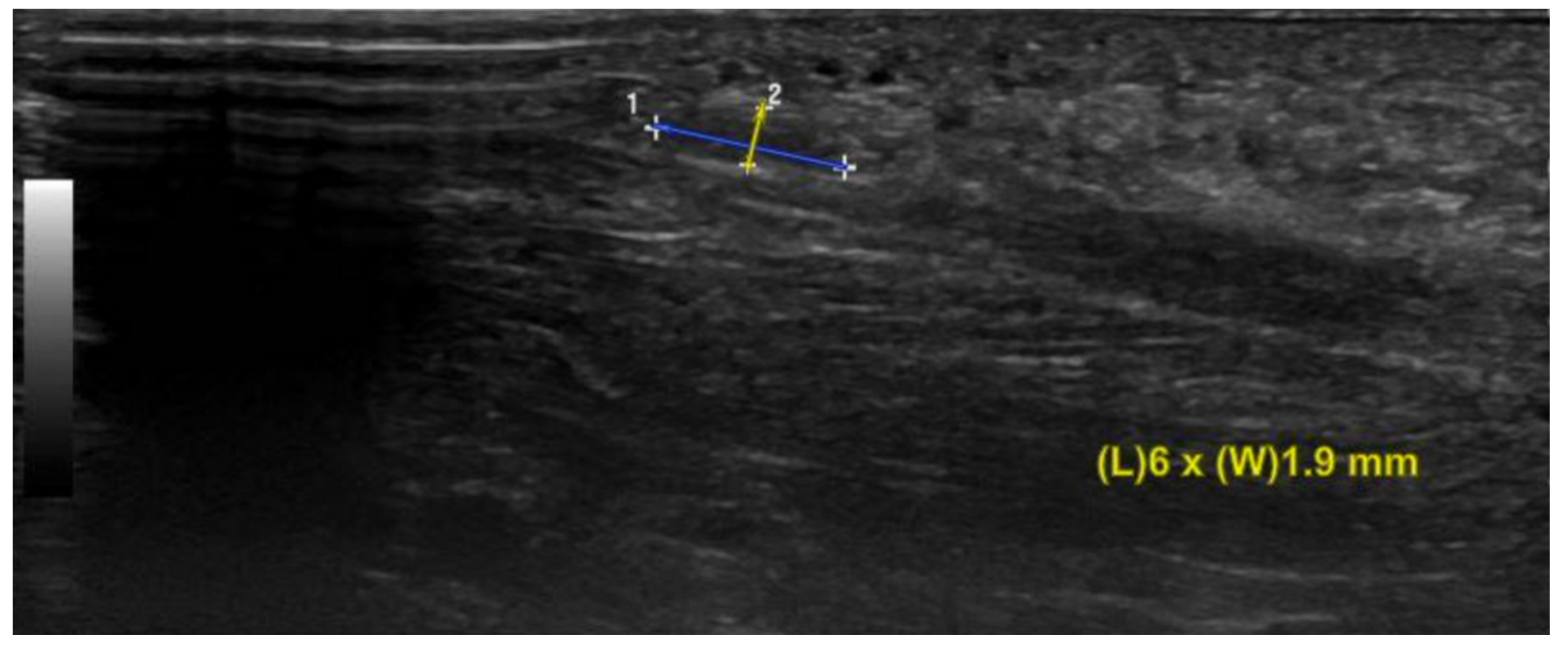

\section{Figure 4}

Case report one, ultrasound scan 12 months post treatment (distal)

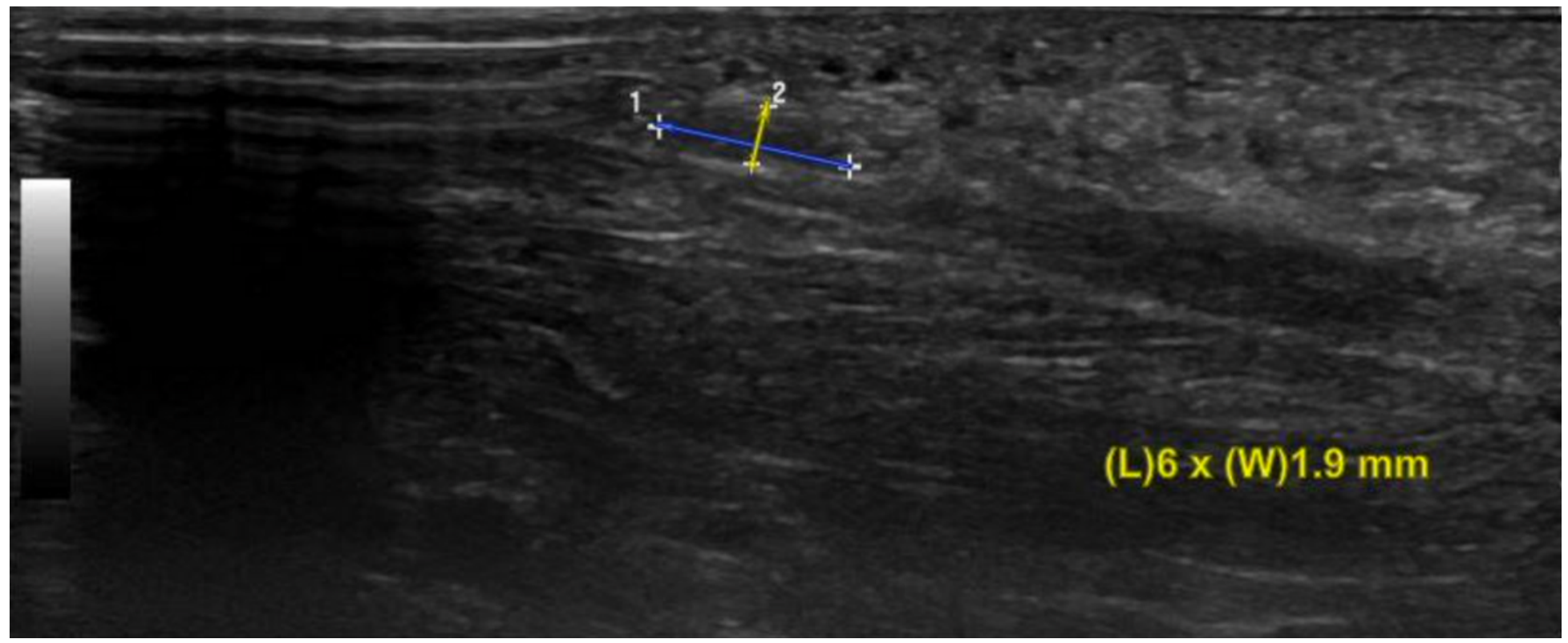

\section{Figure 4}

Case report one, ultrasound scan 12 months post treatment (distal) 


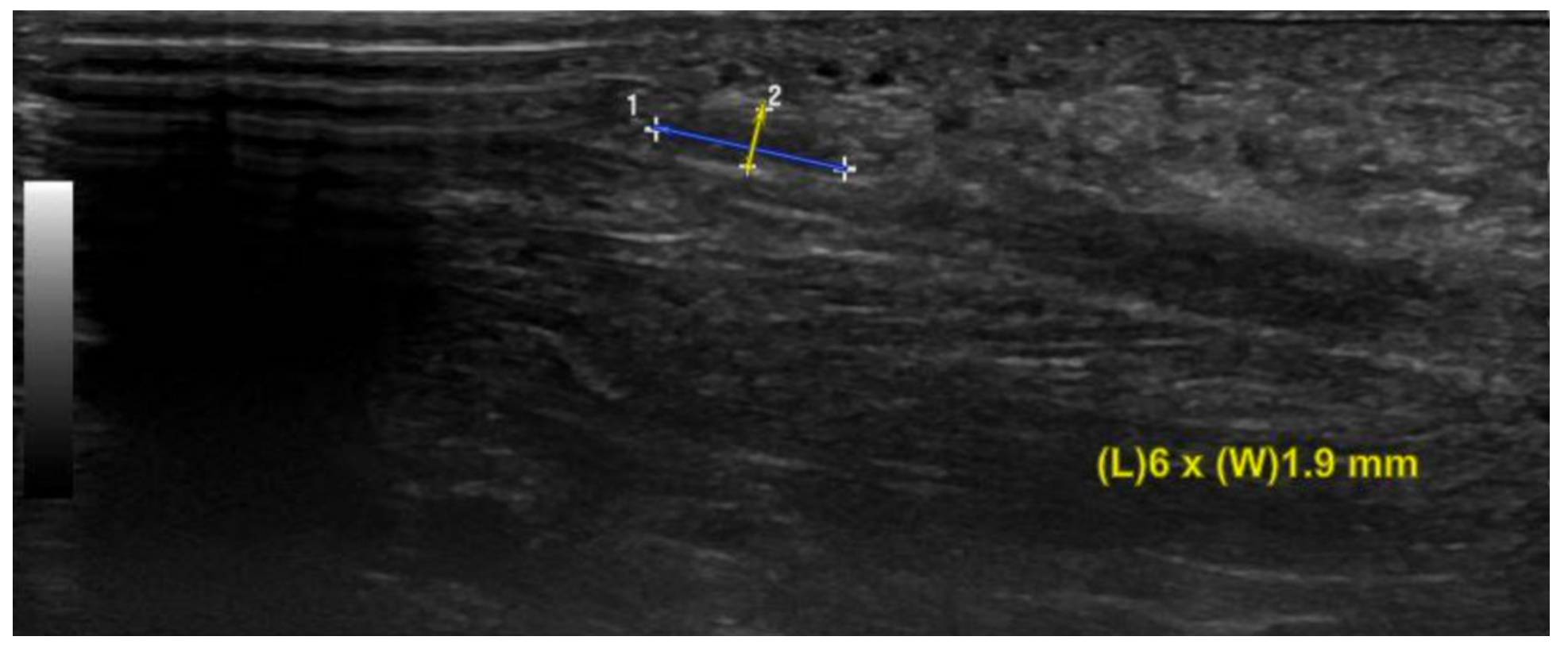

\section{Figure 4}

Case report one, ultrasound scan 12 months post treatment (distal)

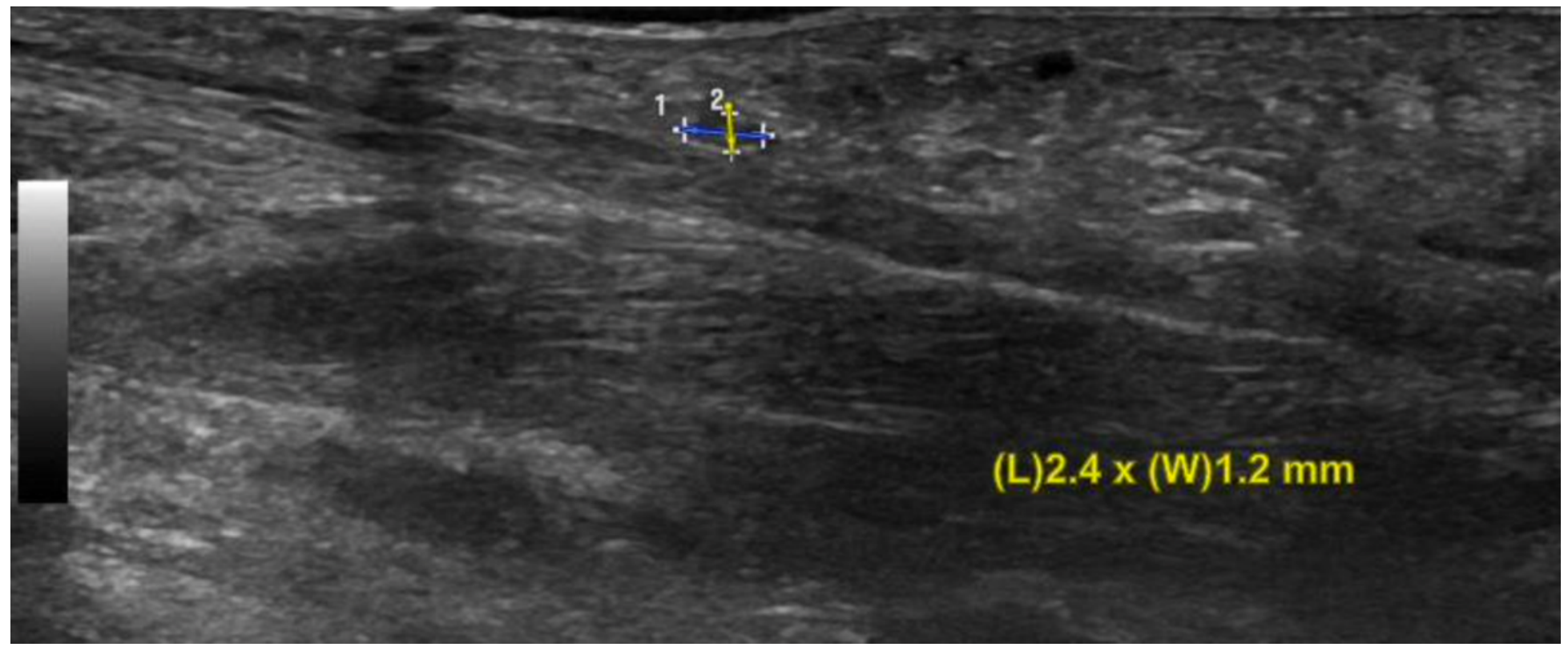

\section{Figure 5}

Case report one, ultrasound scan 12 months post treatment (proximal) 


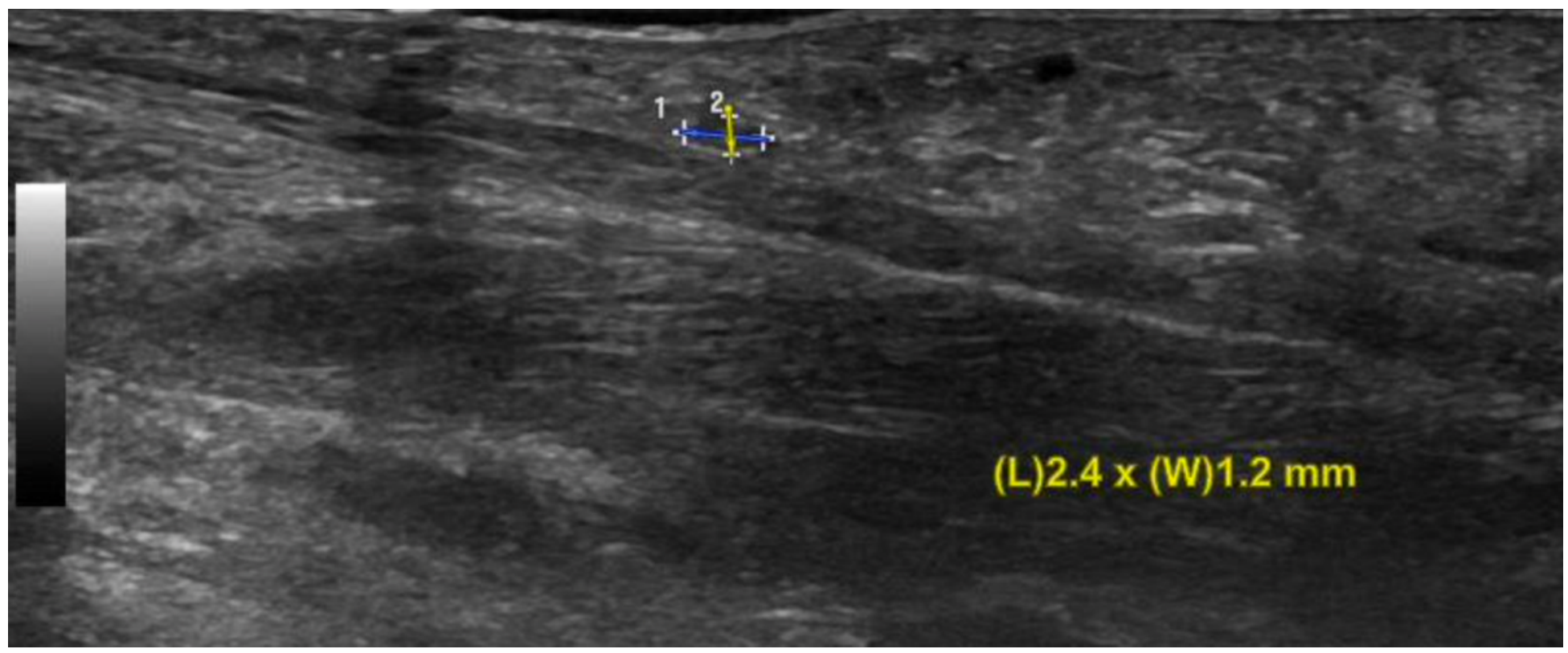

Figure 5

Case report one, ultrasound scan 12 months post treatment (proximal)

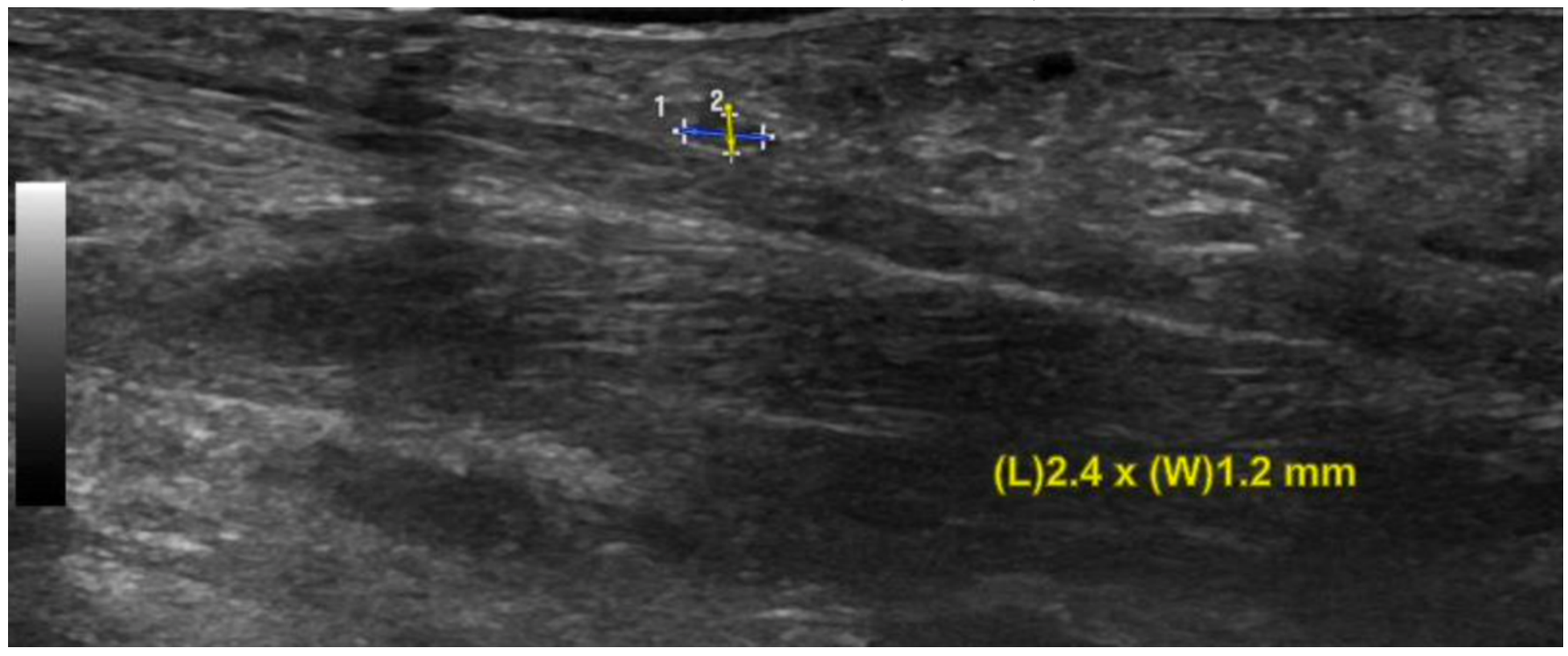

\section{Figure 5}

Case report one, ultrasound scan 12 months post treatment (proximal) 


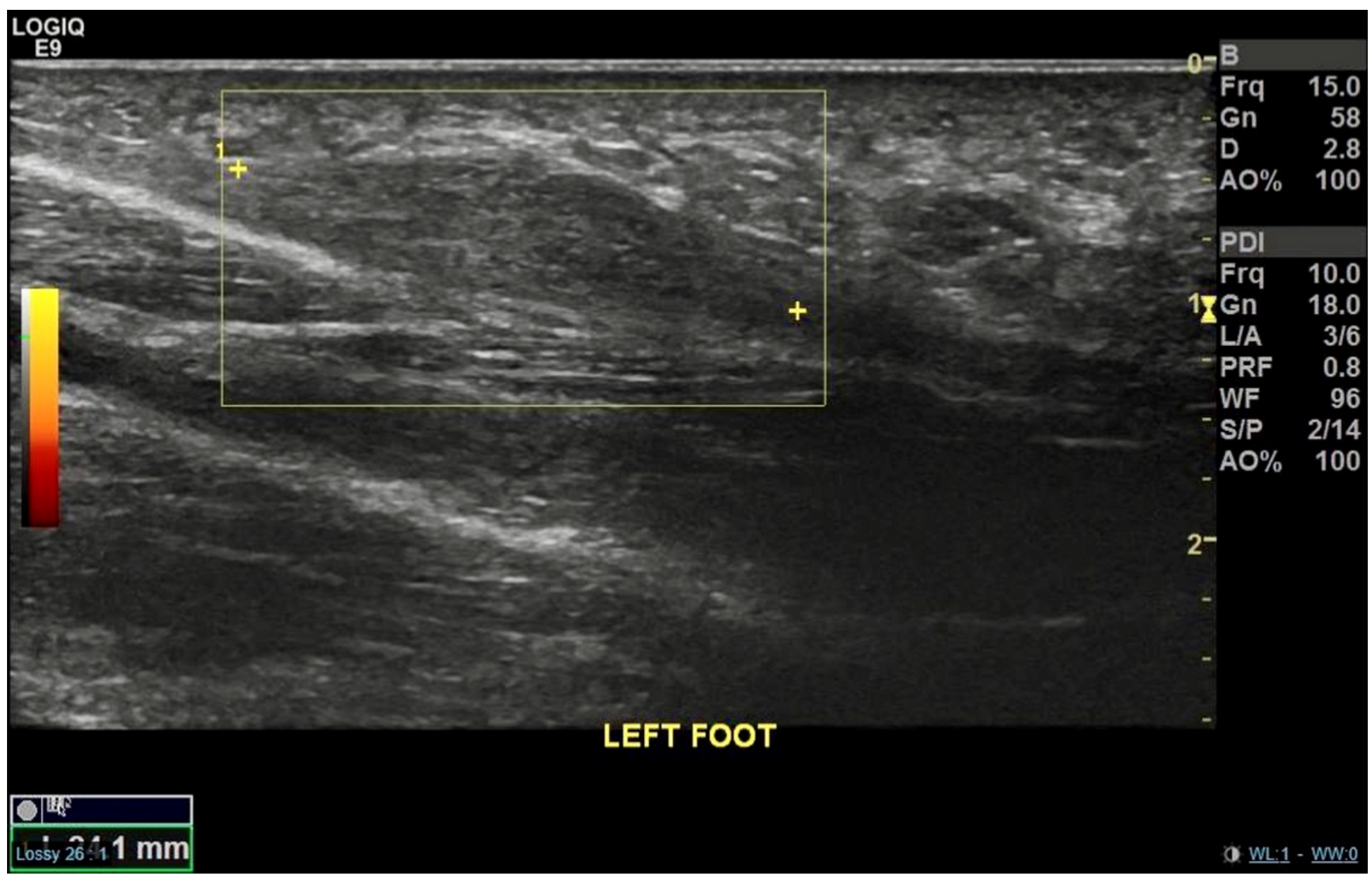

Figure 6

Case report two, pre-treatment ultrasound dimensions 


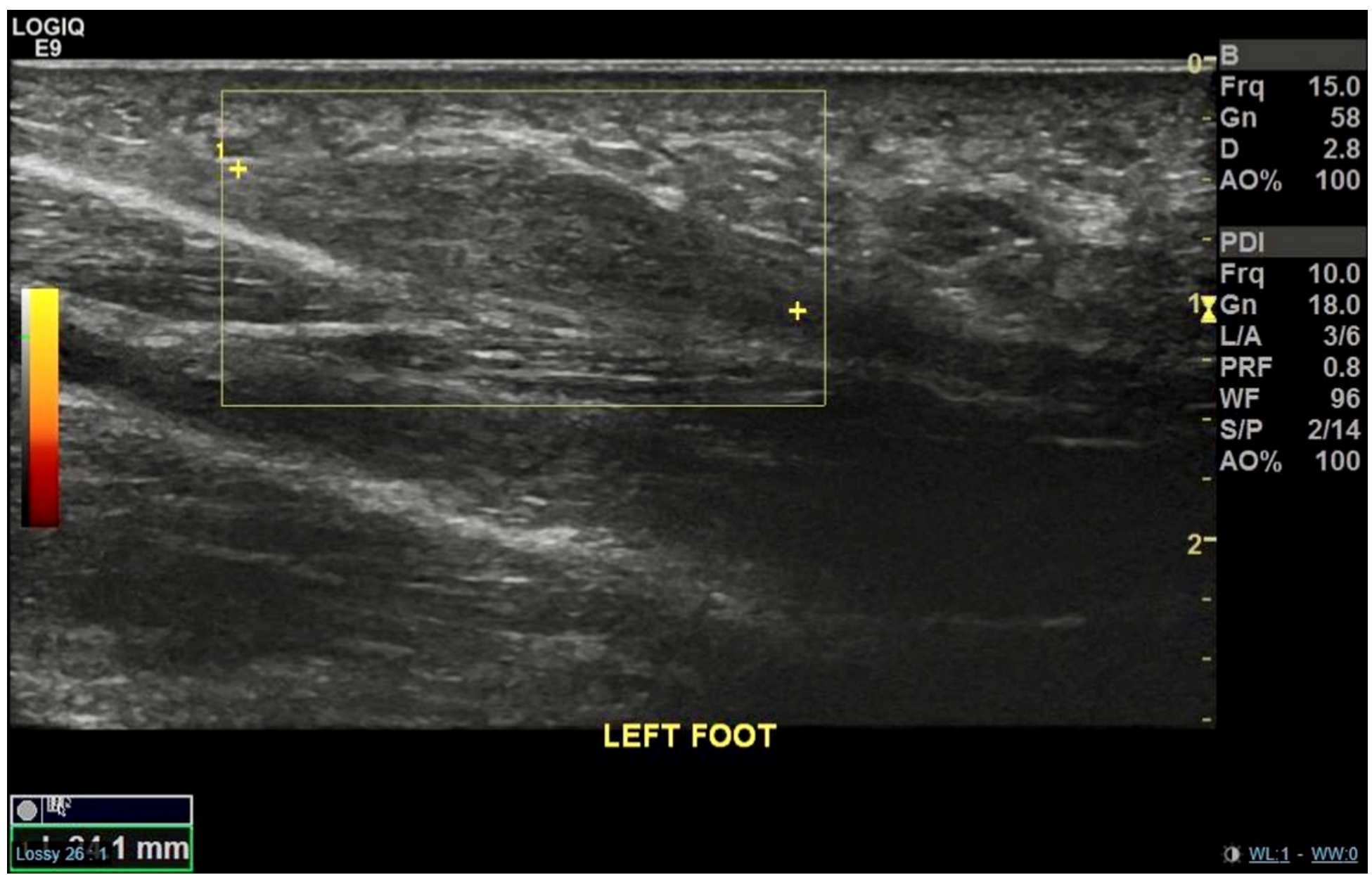

Figure 6

Case report two, pre-treatment ultrasound dimensions 


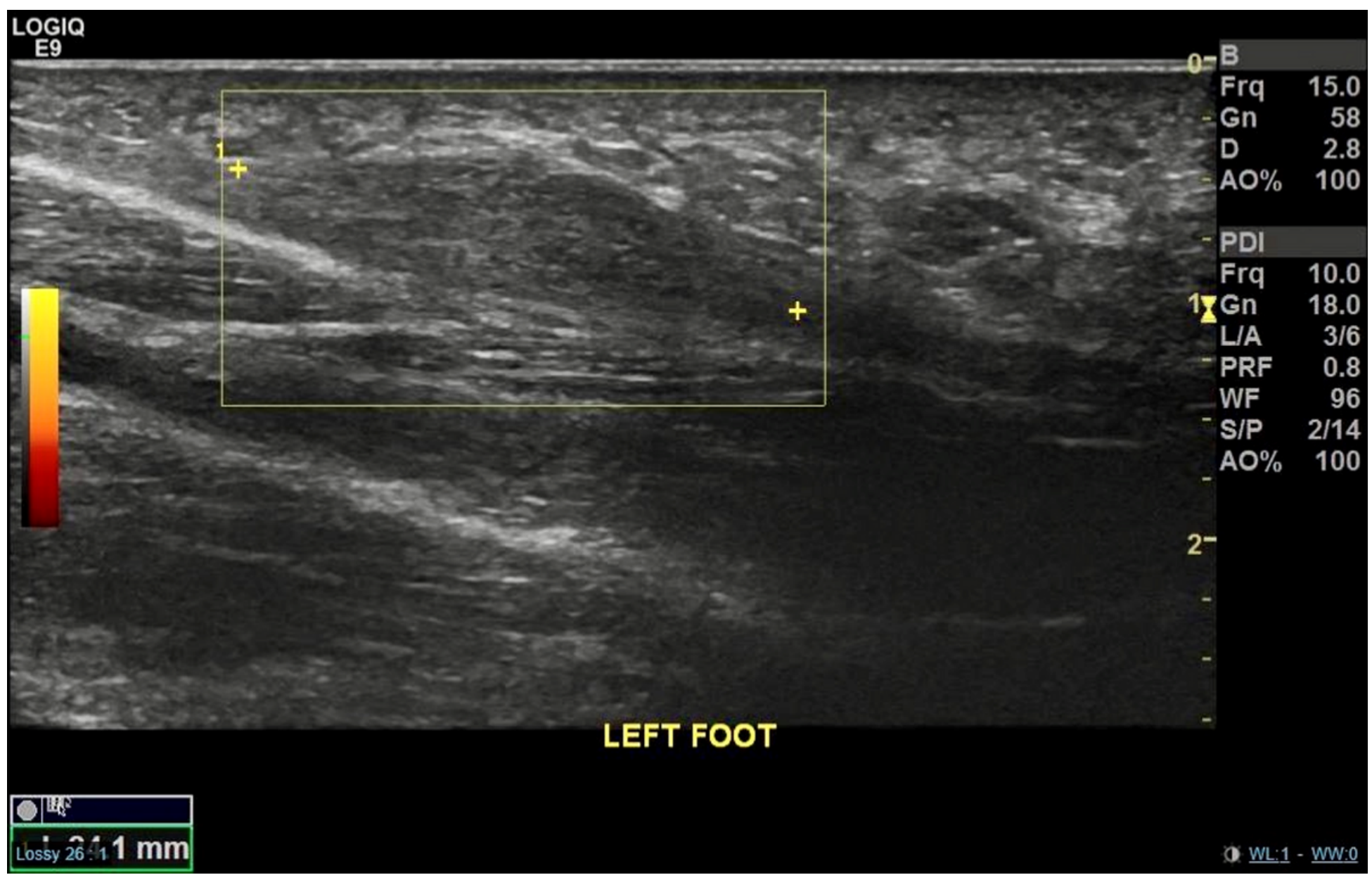

Figure 6

Case report two, pre-treatment ultrasound dimensions 

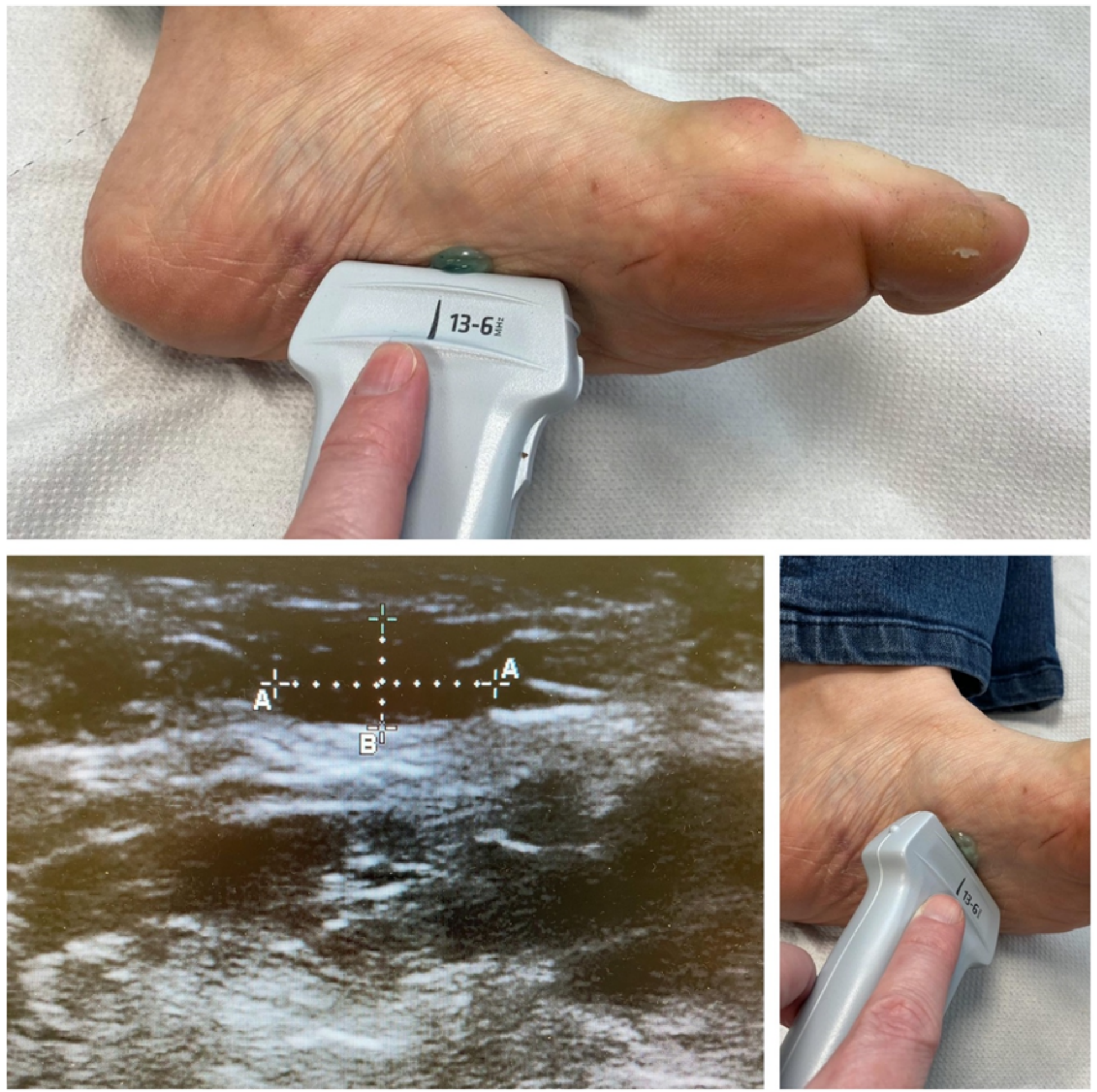

\section{Figure 7}

Case report two, 12 months post treatment ultrasound appearance 

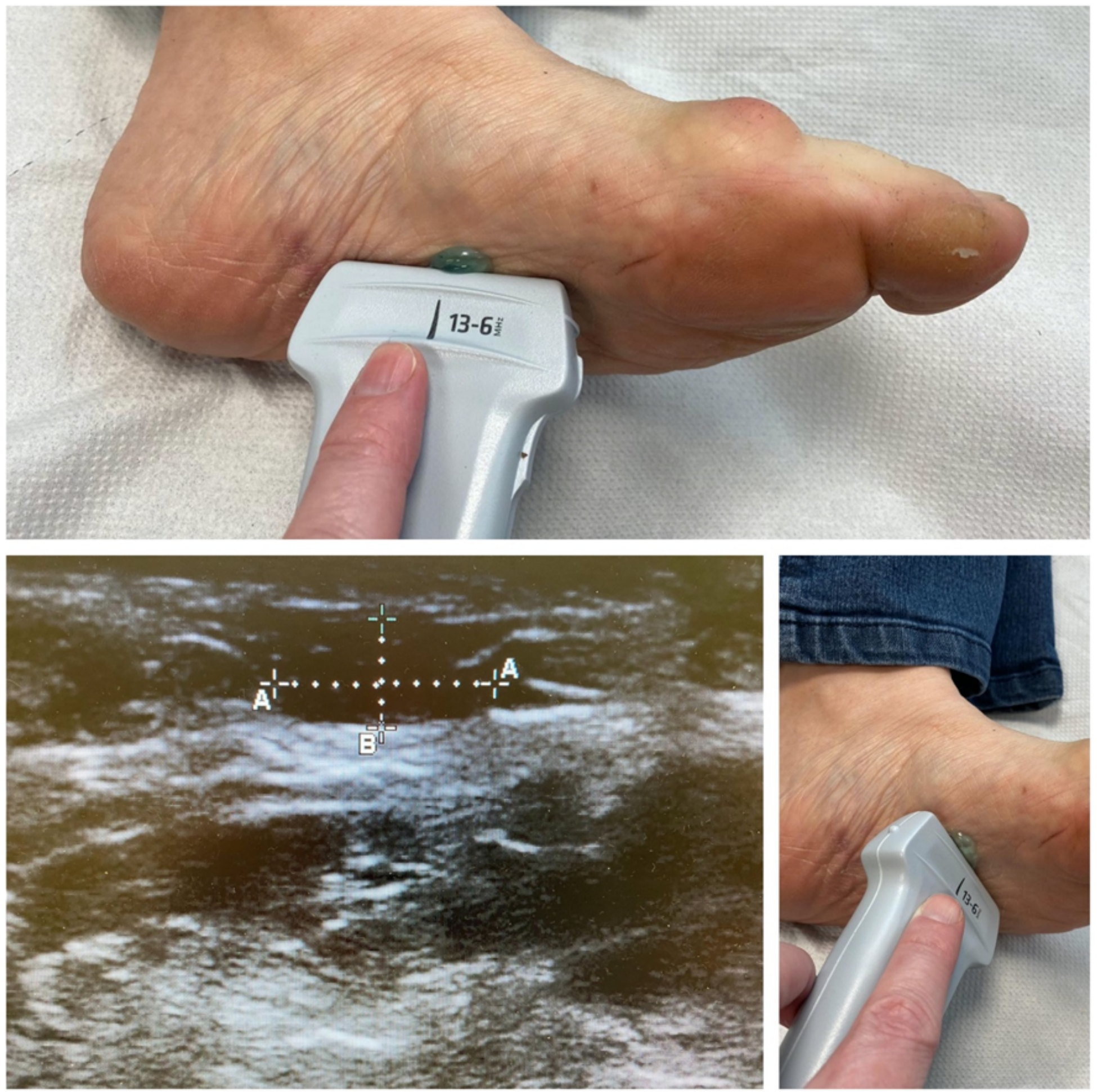

\section{Figure 7}

Case report two, 12 months post treatment ultrasound appearance 

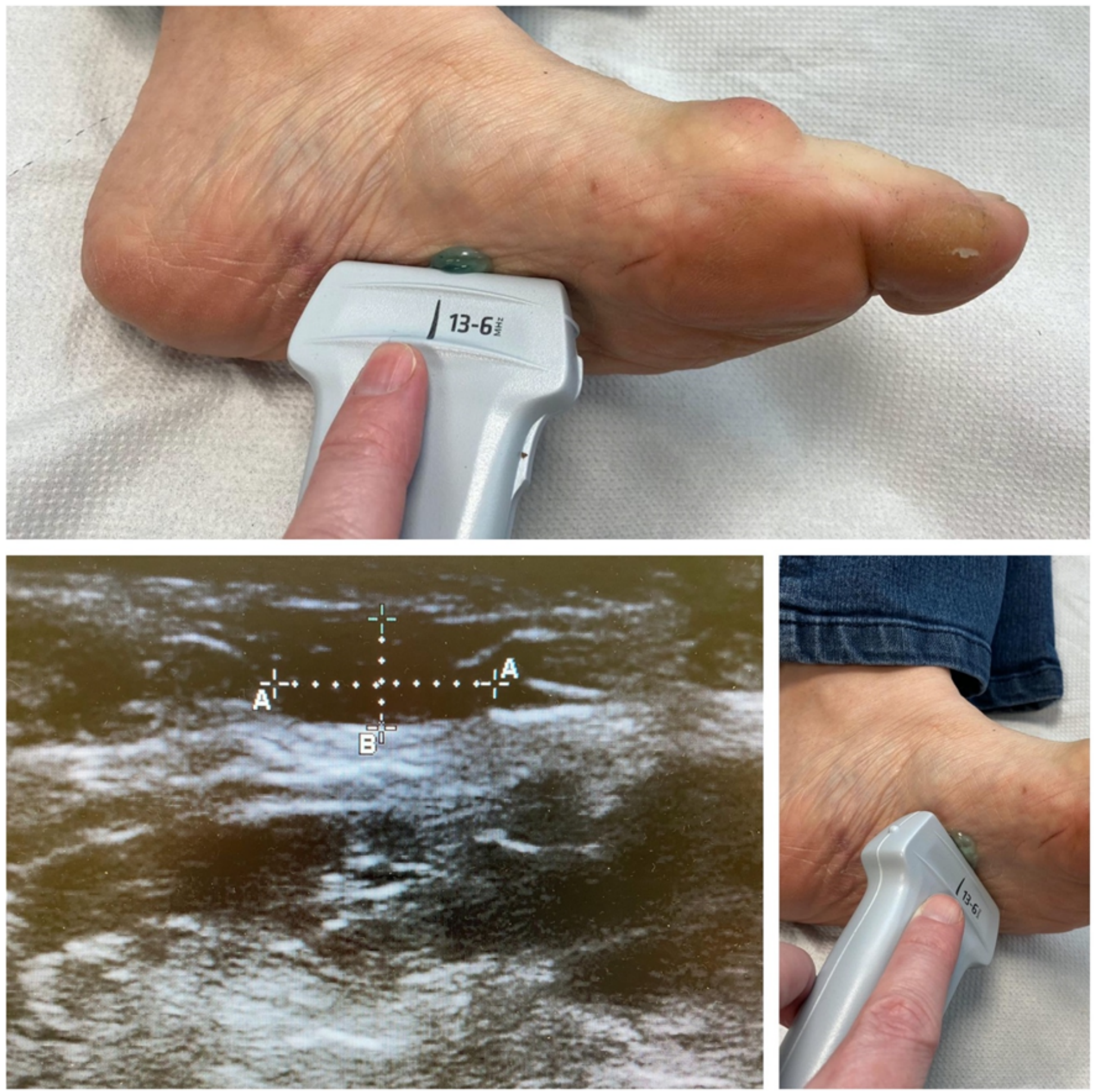

\section{Figure 7}

Case report two, 12 months post treatment ultrasound appearance 